\title{
Benchmarking Concept for Energy Efficiency in the Manufacturing Industry - A Holistic Energy Efficiency Model
}

\author{
Volker Stich, Ulrich Brandenburg, and Sebastian Kropp \\ Institute for Industrial Management at RWTH Aachen University, \\ Pontdriesch 14/16, 52062 Aachen, Germany \\ \{Volker.Stich, Ulrich. Brandenburg, \\ Sebastian.Kropp\}@fir.rwth-aachen.de
}

\begin{abstract}
Determination and comparison of the energy efficiency over all planning levels is one of the key challenges for small and mediums sized enterprises (SME). This is because there is a lack of transparency and information to identify the major energy consumers on plant level as well as on production and machine level. Therefore, there is a need to develop a holistic energy efficiency model which integrates all three planning levels supporting decision makers with the essential information. This paper presents first results from an ongoing benchmark study which is conducted with companies from Austria, Belgium and Germany. First results show, that there is a lack of information integration from the shop-floor to the planning levels which causes SMEs to fail their strategic energy efficiency targets.
\end{abstract}

Keywords: KPI, energy efficiency, ICT, energy management, benchmarking.

\section{Introduction}

Energy efficiency is becoming more and more important for producing industries. Research showed that close to $50 \%$ of the total energy consumed in a typical production plant is used up by producing machines [1]. In addition, due to growing awareness of customers for green products, stricter government regulations and, economically most important, growing prices for energy and resources [2] small and medium sized enterprises (SME) are forced to think about their energy management.

Energy management (EM) is defined as the proactive coordination of procurement, transformation, distribution, and consumption of energy within a company [3]. Within this paper, findings of the project Eco2Cut are presented, which focuses energy consumption and energy procurement of factories.

Today, initiatives for raising the energy efficiency are being conducted on machine and manufacturing process level [4]. Still, it is not possible to benchmark energy consumption as there is a lack of methods and criteria that allow a comparison between the production systems of different companies [5]. Since basic industrial processes 
(e.g. milling, drilling, turning) and products are more or less the same across the world universal indicators need to be found. Industrial energy use indicators can serve as the basis for identifying promising areas to improve energy efficiency on the various planning levels of SMEs. These indicators complement benchmarking but should not act as a substitute [6].

\section{Study Design}

Benchmarking is a commonly used method to enable decision makers to decide based on key performance indicators (KPIs). Hence, benchmarking is a promising tool for monitoring energy efficiency and is therefore essential for an effective energy management.

Today, only few indicators for benchmarking exist especially on production and on the machine level [2].

Therefore, there is the need to develop a holistic energy management model including energy efficiency indicators on all planning levels of the company. This means that decision makers will be given the essential aggregated information to base their decisions on energy efficiency considerations.

Figure 1 illustrates the framework of the study framework. On top there is a strategic design element (EM strategy) where KPIs for the long-term orientation of the company are evaluated. The operative part of the study covers the major layers within a factory:

- Heating, Ventilation and Air Conditioning (HVAC):

Within this layer a company's competence for reusing emitted heat, generating their own energy (photovoltaic, wind energy etc.) and building automation are checked.

- (Energy) Purchase:

This layer evaluates a company's competence to interact with the energy supplier in an efficient manner. In the future concepts like Smart Grids will become more important for industry as well. Therefore, close horizontal information integration is needed.

- Production:

Up to now, energy is not represented adequately as a criterion to plan and control the production. The main cause is that information of the flow of energy is not available due to a lack of vertical information integration from the shop floor to the planning levels. In addition, there is the need to improve energy efficiency on a technological and process level which is subsumed in the production layer. Companies need to replace or substitute technologies and processes that consume a high amount of energy for more efficient technologies and processes. 
To ensure a holistic view on energy efficiency, these three layers are combined with three dimensions of a company namely Organization, Systems and Culture. Figure 1 illustrates nine operative design elements where companies need to gain excellence in order to be energy efficient.

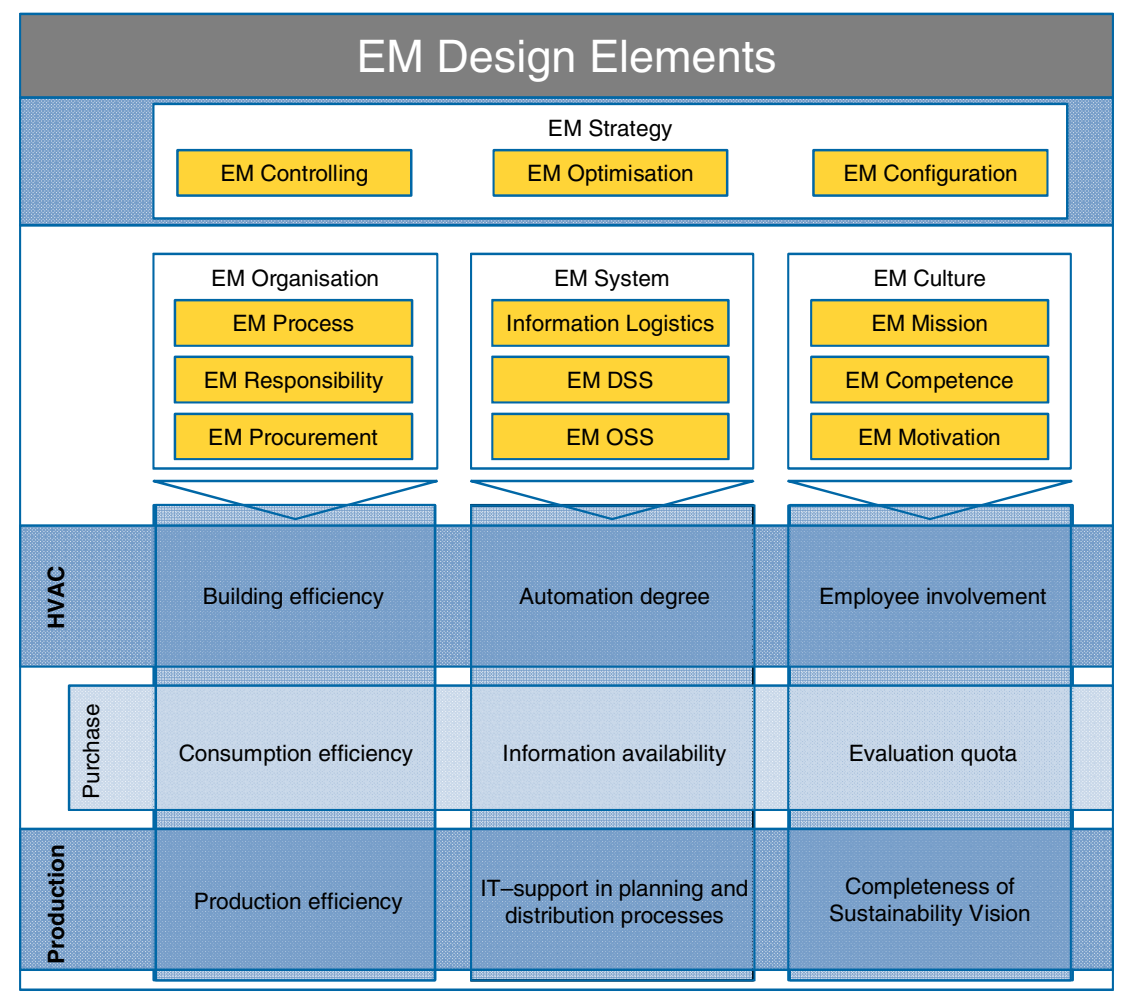

Fig. 1. Framework of the benchmark study

\subsection{Scope of the Study}

The focus of this benchmark study is on small and medium sized companies. Figure 2 gives an overview of the participants of the study ${ }^{1}$.

\footnotetext{
${ }^{1}$ Within the production method multiple answers were possible.
} 

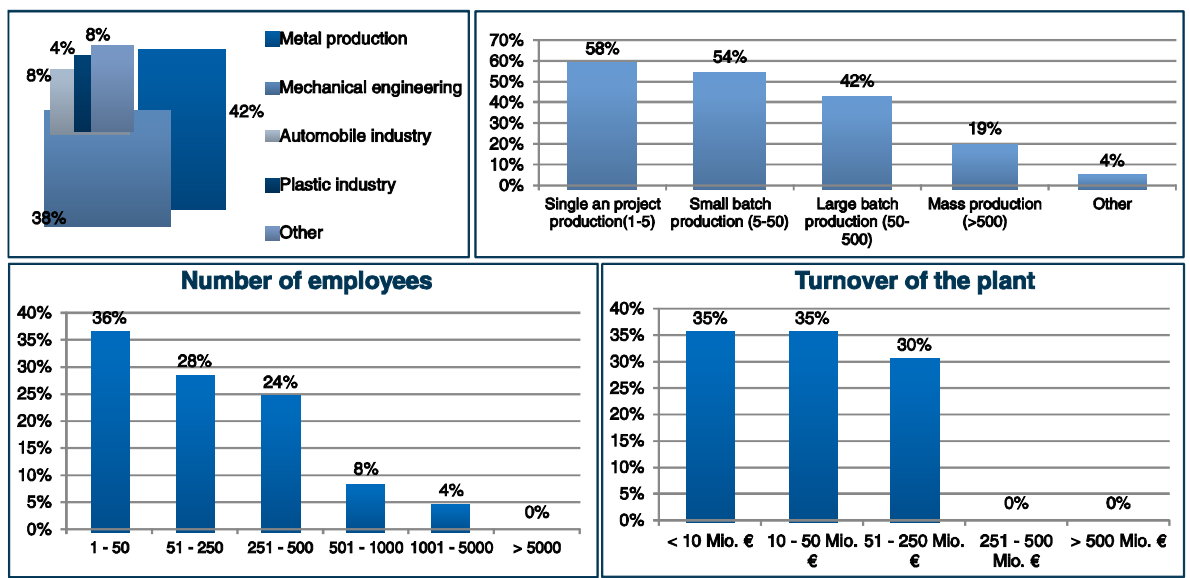

Fig. 2. Characteristics of the study participants

\section{$3 \quad$ Findings and Practical Implications}

\section{EM-Strategy}

The results of the study show that energy efficiency is a very relevant topic for SMEs. The study gave the following implications:

- More than $75 \%$ stated that energy efficiency is important to the management.

- $52 \%$ of the companies evaluate projects for improving the energy efficiency after their implementation.

- More than 50\% agree to that the competence of measuring, controlling and analysing of energy data contributes towards a competitive advantage

- $55 \%$ stated that the changes of energy consumption are a strategic target figure.

- $\quad$ Only $44 \%$ stated that they obtained the planned energy reduction.

HVAC

The results of the study show that there is still a lot of work to do on the HVAC level:

- Only $4 \%$ of the companies use photovoltaic to generate energy. Where photovoltaic is used, it covers more than $60 \%$ of the total demand.

- $5 \%$ of the companies use waterpower. Where waterpower is used, it covers less than $30 \%$ of the total demand.

- Neither of the companies uses solar thermal energy, geothermal energy or wind energy.

- About $65 \%$ of the companies claim that the heating in the office buildings is still manually regulated.

- Automation of HVAC devices as well as lightning is not commonly used. 


\section{Purchase}

- Less than $50 \%$ of the participating companies do an accurate energy consumption planning for the forthcoming year.

- $52 \%$ of the companies analyse their load profiles. Out of these $54 \%$ use computer-based assessments and $46 \%$ a manual analysis.

- On the other hand companies do not seem to measure KW-peaks (only $5 \%$ ) and the load profile fluctuation (only 18\%).

- $62 \%$ of the companies discussed possibilities to reduce peak loads with their supplier.

- $73 \%$ of the companies regularly invite offers from different energy suppliers.

\section{Production}

- Companies put quite a high effort into raising their energy efficiency in production from an EM-Organisation and EM-Culture point of view. For example, companies optimize their compressed-air systems or turn-off machines during idle times.

- From an EM-System point of view there is a big lack for a support of the production planning and controlling in terms of energy efficiency.

- More than $75 \%$ of the companies more or less agree that the integration of IT-systems would help them in their decision-making and operative planning.

- More than $75 \%$ more or less agree that only real-time processing of machine and operating data within the production planning and controlling leads to transparency and competence in the field of energy management.

\section{Conclusions and Further Research}

The benchmark study conducted within the project Eco2Cut reveals that energy efficiency and energy management are very much in the focus of SMEs within the manufacturing industry. The study clearly shows that SMEs try to integrate energy efficiency considerations into their corporate strategy. However, it became obvious that companies often lack the transparency, skill and technology to succeed with their strategic energy targets. With the results of the Eco2Cut benchmark study companies are provided with a holistic energy efficiency model that helps them identify the levers for increasing their energy efficiency. Key findings of the study were:

- SMEs strategically consider energy efficiency.

- SMEs conduct energy efficiency actions/projects on the shop floor level but without following a consistent strategy.

- SMEs lack the transparency of energy consumption due to a highly disintegrated ICT-infrastructure.

- SMEs neglect the possibilities of reducing energy costs on the supply side. 
Therefore, future research should focus on integrating existing IT-systems with energy management systems to allow future calculations of energy consumed by products throughout the production process. Information and communication technologies (ICT) enable energy efficient manufacturing by integrating real-time data from the Manufacturing Execution Systems (MES) on the shop-floor into the Enterprise Resource Planning Systems (ERP) [2], [7]. Real-time data of the machines supports low-energy resource planning as, for example, idle times can be planned based on the order situation. By simulating alternative production processes within the ERP-System energy efficiency considerations can be included in machine procurement.

Consequently, this would add to the internet-of-things approach where products are given to ability to find their optimal (e.g. most energy-efficient) path through production. As a prerequisite companies need to conduct a thoroughly energy flow analysis to identify where information about energy consumption is need and where this information can be collected from shop floor to planning levels. Based on this vertical integration of the flow of energy and information companies can interact with their suppliers to negotiate tailor-made energy tariffs. Consequently, this would lead to the adaption of the Smart-Grids approach for the manufacturing industry.

\section{References}

[1] Klocke, F., Brühl, J., Döbbeler, B., Essig, C., Hein, C.: Nachhaltige Produktion. In: AWK Aachener Werkzeugmaschinen-Kolloquium (Hrsg.): Wettbewerbsfaktor Produktionstechnik. Aachener Perspektiven, Aachen (2011)

[2] Bunse, K.: Integrating energy efficiency performance in production management - gap analysis between industrial needs and scientific literature. Journal of Cleaner Production (2011)

[3] Grahl, A.: Handbuch für betriebliches Energiemanagement. Systematisch Energiekosten senken, Berlin (2009)

[4] Brecher, C., Bäumler, S., Bode, H.: Ressourceneffizienz im Werkzeugmaschinenbau. In: AWK Aachener Werkzeugmaschinen-Kolloquium (Hrsg.): Wettbewerbsfaktor Produktionstechnik. Aachener Perspektiven, Aachen (2011)

[5] Gesellschaft, F.: Energieeffizienz in der Produktion. Untersuchung zum Handlungs- und Forschungsbedarf (2008)

[6] International Energy Agency (IEA): Tracking Industrial Energy Efficiency and CO2 Emissions, Paris (2007)

[7] European Commission: ICT and e-Business for an Innovative and Sustainable Economy. 7th Synthesis Report of the Sectoral e-Business Watch (2010) 